\title{
Comparative Analysis of the Environmental Performance of Delivery Routes in the City Center and Peri-Urban Area of Madrid
}

\author{
Alessandra Boggio-Marzet ${ }^{1, *(\mathbb{D}}$, Andrés Monzón ${ }^{1}\left(\mathbb{D}\right.$, Pablo Luque-Rodríguez $^{2} \mathbb{D}$ and Daniel Álvarez-Mántaras ${ }^{2} \mathbb{D}$ \\ 1 TRANSyT-Centro de Investigación del Transporte, Universidad Politécnica de Madrid, Escuela de Ingenieros \\ de Caminos, Canales y Puertos, Calle del Prof. Aranguren 3, 28040 Madrid, Spain; andres.monzon@upm.es \\ 2 Escuela Politécnica de Ingeniería, Campus de Gijón, Universidad de Oviedo, s/n, 33203 Gijón, Spain; \\ luque@uniovi.es (P.L.-R.); mantaras@uniovi.es (D.Á.-M.) \\ * Correspondence: alessandra.boggiomarzet@upm.es; Tel.: +34-910-674-237
}

check for updates

Citation: Boggio-Marzet, A.; Monzón, A.; Luque-Rodríguez, P.; Álvarez-Mántaras, D. Comparative Analysis of the Environmental Performance of Delivery Routes in the City Center and Peri-Urban Area of Madrid. Atmosphere 2021, 12, 1233. https://doi.org/10.3390/

atmos12101233

Academic Editor: Mark Theobald

Received: 30 July 2021

Accepted: 17 September 2021

Published: 22 September 2021

Publisher's Note: MDPI stays neutral with regard to jurisdictional claims in published maps and institutional affiliations.

Copyright: (c) 2021 by the authors. Licensee MDPI, Basel, Switzerland. This article is an open access article distributed under the terms and conditions of the Creative Commons Attribution (CC BY) license (https:/ / creativecommons.org/licenses/by/ $4.0 /)$.

\begin{abstract}
Cities are experiencing a process of suburbanization and last-mile delivery has grown, worsening traffic congestion, pollutant emissions, and citizens' quality of life. Based on a real-life case study, this research compares the environmental performance of different delivery routes carried out by Diesel Light-Duty Vehicles (LDV) according to delivery area, city center or peri-urban. Some 242 delivery routes performed by thirteen drivers were recorded for one month, including instantaneous GPS position, speed, and other parameters (7262 km travelled). Four different delivery routes typologies were compared, and the drag function of the vehicles was characterized. It enabled calibration and modelling dynamics to calculate fuel consumption and pollutant emissions according to delivery routes. The results show that pedestrian crossings, traffic lights, and traffic congestion reduce the average operating speed by up to $57 \%$ in the city center and consequently overall energy efficiency. Our results highlight the urgency of replacing diesel LDV for deliveries in the city center with no-motorized transport modes and of implementing intermodality to cover deliveries in residential peri-urban areas. Due to low speeds and frequent start-stops, the efficiency of vehicles in these areas is reduced to a minimum and pollutant emissions increase. The outputs set a basis for recommendations for using LDV only for delivery routes with less traffic interruptions and foster intermodal solutions.
\end{abstract}

Keywords: last-mile delivery; energy efficiency; fuel consumption; pollutant emissions; optimization of delivery route; Madrid region

\section{Introduction}

The great transformation we are experiencing within the current process of globalization sees the mobility of people and goods grow at an astonishing rate and it drives logistics distribution in new directions, creating a highly dynamic scenario of perspectives. The population growth, the increasing of e-commerce sales, and the expectations of shorter delivery times are one of the main factors putting extreme pressure on urban logistics. Indeed, although goods distribution is of fundamental importance for the prosperity of a country and its citizens, it increases side effects such as congestion, accidents, air pollution, and noise.

Other economic sectors, such as households and industry, have drastically reduced their pollutant emissions compared to the 1990 level (Kyoto Protocol); on the contrary, transport emissions have increased, being 29\% above the 1990 levels in 2018. In particular, road transport is the main culprit compared to other modes, both for passengers and goods [1,2].

Transport activity across Europe is high and continuously growing. The European Union [3] estimations that passenger transport will increase by $42 \%$ by 2050 , and freight 
transport by $60 \%$. To deal with such growth, solutions that will be proposed must aim to strike a balance between having efficient urban logistics systems and sustainable levels of externalities, with particular regards to traffic congestion, pollutant emissions, and safety $[4,5]$.

According to the International Transport Forum, global transport demand is estimated to triple by 2050, which would mean that carbon emissions in ordinary circumstances would double [6]. Nonetheless, the European Union aims to be climate-neutral by 2050. This is an ambitious target when it comes to tackling climate change and reducing the negative impacts of human activities on the environment and society.

Nowadays, with more people living in cities and a higher volume of online transactions, there is more pressure on urban freight transport. This is especially true with the emergence of $Q$-commerce (a new battlefield in the hyper competitive delivery space for quick deliveries), which is a new model of e-commerce in which speed, convenience, and customer service are the key factors [7].

Previous studies estimated that urban freight transport accounts for up to $30 \%$ of total traffic emissions depending on the local context; in larger European metropolitan areas, it is responsible for $33 \%$ of $\mathrm{NO}_{x}$ emissions [4]. In order to counter current trends and meet the targets of the European Union, a holistic approach is required, and gains in transport efficiency must be integrated in emission reduction policies.

The literature has investigated several strategies to reduce the negative impacts of urban freight transport on cities and citizens mainly based on the optimization of traditional delivery practices, or on innovative solutions to make last-mile deliveries (LMD) more efficient [8]. Among them, solutions that directly lead to a decrease of emissions can be clustered into five groups, according to the Alliance for Logistics Innovation through Collaboration in Europe-ALICE [9]. These are: proper management of growth in freight demand; smart use and combination of different transport modes; sharing fleets and making optimized use of them by reducing the carbon content of energy sources; adopting a holistic approach to improving the energy efficiency of fleets, including improving the driving behavior and route planning skills; and lastly, making use of information and communication technology (ICT).

Short-term solutions would save time to implement more advanced long-term ones. Thus, short-term research and efforts must focus on leveraging and finding new opportunities for improving efficiency in urban freight transport, in terms of both optimization and innovation. Among these, one of the main options to optimize traditional strategies (i.e., LMD carried out by Light Duty Vehicles_LDVs) is to improve route planning skills since it has been demonstrated that proper route planning can save up to $20 \%$ of fuel consumption and reduce the corresponding emissions [10-12].

Motivated by those results and following the recommendation of the literature stating the need to distinguish between different geographical contexts when planning urban deliveries $[4,5,13]$, a data collection campaign was carried out in the metropolitan area of Madrid, in collaboration with the main logistics company of Spain, Correos. For one month, 13 carriers from different depots (one located in the city center and the other in the peri-urban area) drove the same LDV model to perform their deliveries, while GPS position, speed, and other engine parameters were recorded instantaneously. In a second step, this research applies and calibrates an energy demand model to compare the energy efficiency of LDV while delivering along different delivery routes which are local roads, mixed road sections, or crossing residential areas. Thus, this research identifies the operative features of LMD according to the delivery area - city center or peri-urban-and it examines the energy efficiency and the environmental impacts associated with LMD carried out by diesel LDV in both quantitative and qualitative terms.

The paper is structured as follows. Section 2 provides a brief review of LMD in urban areas as well as the importance of the geographical context and delivery route to plan strategic solutions to reduce pollutant emissions in LMD. Section 3 describes the case study, the data collection campaign, and the delivery routes selected to compare pollutant 
emissions according to the delivery area. Section 4 discusses the energy consumption model developed for this study and its calibration according to the LDV used in the field test. Section 5 presents the analysis of the results, while the main conclusions, contributions, and policy recommendations are discussed in Section 6.

\section{Last-Mile Delivery in Urban Areas}

This section first discusses the current state of LMD in urban areas and refers to the current trends driving LMD. Then, the importance of the geographical context when planning a strategic solution for LMD is elaborated. Finally, the importance of the delivery route and its environmental performance are considered, and the research objectives of this study are defined.

\subsection{Current State and Driving Forces}

Economic growth in cities and urban areas strategically depends on having a sophisticated freight transport and logistics system, as these make regions and countries more efficient. Nowadays, no urban area could exist without a reliable freight transport system [14]. However, goods distribution has become a pressing issue even in the most developed urban areas [15].

Due to the growth in freight distribution, there is an increasing number of vehicles and companies operating in cities. Goods distribution in urban areas, together with private traffic flows, are some of the main sources of energy consumption, air pollution, and noise. A recent study in EU countries shows that in $60 \%$ of the cities, there are significant difficulties in urban logistics management: $55 \%$ of vehicle emissions are caused by goods distribution of which $40 \%$ are delivered to city centers [16,17].

In recent years, important trends have put pressure on urban freight transport and have consequently led to increased environmental problems. First, there is a trend in which the population has shifted from rural settlements to urban areas-in 2020, for the first time in history more people lived in urban than rural areas [18]. In 1950, only one-third of the world's population lived in cities, while by 2050, the rural population is expected to be only one-third of the total. A shift in this paradigm has occurred over the course of one century [13]. Second, e-commerce has steadily grown, and some of the world's most sophisticated markets can be found in the European Union. The volume of online shopping worldwide tripled between 2014 and 2020 and is predicted to increase almost five-fold by 2024 [19]. Boosted by the COVID-19 pandemic, it has produced a sharp increase in freight activities and consequently in city traffic. The pandemic, indeed, had a great effect as many people turned to online ordering when local shops closed. It is largely expected that COVID-19 will result in a huge and permanent leap forward in e-commerce that otherwise would have taken another 5-10 years [20]. Third, consumers increasingly participate in ecommerce with the expectation of shorter delivery times. This requires delivery services to become more responsive. By 2023, 78\% of logistics companies considered in [21] expect to provide same-day deliveries, and by $2028,39 \%$ of logistics companies anticipate deliveries within a two-hour window.

LMD accounts for $53 \%$ of the total shipping cost and $41 \%$ of the total supply chain cost [22]. For parcels, Gevaers [22] estimates that the last mile represents between $13 \%$ and $75 \%$ of the total logistics cost. Despite this, the LMD is necessary and inevitable because, for now, not all goods needed are available at our doorstep. In the light of this, the right question is not why to transport goods, but how to deliver them [23]. The objectives of efficiency, effectiveness, economy, and environmental sustainability must be achieved.

Nonetheless, the achievement of adequate energy efficiency is a major challenge during LMD since these are based on individual orders which must be picked up and delivered to different locations. In this context, inefficiencies and delivery challenges for freight carriers have exacerbated considerably in inner-city areas and thus require optimized delivery planning [24]. 


\subsection{The Importance of the Geographical Context}

The significance of LMD externalities, e.g., congestion, pollution, and noise, varies according to the city size, and there are relevant differences between deliveries carried out in large conurbations and small or medium sized cities [25]. Previous researchers point to the need to differentiate between geographical, social, and economic contexts while planning LMD. This is because the main operational features can vary considerably according to urban environments and road networks $[4,5,13]$. In city centers, the road network is usually entirely composed of local roads, with speed limits under $50 \mathrm{~km} / \mathrm{h}$, while in peri-urban areas the road network is usually "mixed", containing high-speed roads as well as arterial urban roads or large avenues.

As the literature demonstrates, several suitable solutions can be applied to reduce the externalities of LMD; however, their efficiency depends on the location where these solutions are implemented. Depending on the urban set-up indeed, it can be more efficient for example to re-locate the distribution centers, change the type of vehicle fleet, implement eco-routing driving systems, adopt advanced ITS solutions, try to avoid empty trips, or reserve parking lots.

Savelsberg and Woensel [26] pointed out that geographical, economic, social, and cultural circumstances affect city logistics and the perception of people regarding the externalities mentioned before. A review work by Browne et al. [27] detailed the impacts of various initiatives (i.e., consolidation centers, low emission zones, new and greener vehicles) applied in four countries around the world-the UK, Japan, Netherlands, and France. It showed that depending on the area of implementation and their intensity, the same initiatives might produce different results in terms of reducing social and environmental impacts. Similarly, Navarro et al. [28] and Ermagun et al. [29] highlighted the importance of considering the characteristics of the area in which the measure is implemented, when defining a strategic solution. Both population density and road access have a direct influence on the energy consumption of a delivery route [30,31], along with the delivery area and road section typology.

\subsection{Delivery Routes and Research Objectives}

The last mile extends from a few tens of meters to a large distance of tens of kilometers, as logistics facilities have been relocated to suburban areas while many businesses and retailers remain in inner-city areas $[13,24]$. Different delivery distances should mean different delivery methods and modes of transport. Respectively, the environmental impacts of LMD can also differ widely. Considering the traditional method of delivery by LDV, it is therefore essential to study optimal routes in terms of environmental and operational efficiency.

The routes covered in urban goods distribution may be fixed routes for visiting preestablished points, or dynamic routes which are programmed daily according to demand. Dynamic route planning is much more complex and minimizing the distance or time is key for achieving all scheduled deliveries [11]. However, the energy consumption and thus cost for the delivery company may vary considerably depending on whether time or distance is minimized.

Normally, even if drivers know the local areas and routes, they face unpredictable delivery constraints including traffic congestion, change of weather conditions, construction closures, etc. All these challenges make drivers inefficient when it comes to planning optimal routes. On the other hand, there are route planning solutions which create optimal route plans based on real-time traffic, estimated time of arrival, and other criteria.

Route planning software enables multiple-trip delivery routes to be planned and minimizes the time or kilometers travelled. This can save between 10 and $20 \%$ of transport costs [11]. However, most of them are concerned with minimizing the total transportation cost based on reducing the distance travelled, the travel time, or the fleet size [32]. Thus, the reduction of pollutant emissions is considered only indirectly as a significant but "secondary" consequence (achieved through a reduction of travel time, distance, or fleet). 
Only recently have there been studies focused on directly reducing the environmental impact of LMD by choosing the appropriate route. According to Egles and Dan Black [33], no such studies existed until 10 years ago. In addition, most research on route planning presented algorithms based on simulations in a specific area, without considering the disparity of environmental features $[34,35]$.

Cattaruzza et al. [10] identified four main challenges in the optimization of vehicle routes for urban goods movements: time-dependency of travel times, organization of the distribution in multi-levels, dynamics of the cities, and organization of routes with multiple trips. Specifically, they call for research concerning the last challenge.

To address this gap and considering the scarcity of real data available from logistics companies - as data might be part of their business strategy-we conducted a real-life experiment to identify the features of LMD according to the geographical context. Thus, the research objectives are as follows: first, to define the main features of LMD operations carried out by the same logistics company according to the delivery area, either city center or peri-urban. Second, to compare the energy efficiency of LMD carried out with the same LDV model along different multiple-trip delivery routes. Third, to study the extent to which pollutant emissions vary for LMD routes.

\section{The Madrid Case of Study}

The case study took place in Spain, within the metropolitan area of Madrid, which covers $8030 \mathrm{~km}^{2}$ and in which the proportion of urbanized land is $11 \%$. It has a total population of 6.6 million inhabitants, half of whom are concentrated in the city of Madrid [26], with an average density of 54 inhabitants per hectare.

The case study was defined to analyze real data collected during a field test for lastmile parcel deliveries carried out by the National Spanish Postal company (Correos). It has 51,000 employees countrywide with more than 3600 million shipments per year. Within the Madrid region, Correos owns 27 depots which distribute parcels by LDV. Fifteen of the 27 depots are located inside the city.

Two of these depots, one located in the city center and the other in the northwestern peri-urban area of Madrid, were involved in the field test. The two delivery areas have different characteristics. One of the two depots provided by Correos is in the Las Rozas municipality $\left(19,471 \mathrm{inh} / \mathrm{km}^{2}\right)$ in the northwestern part of the metropolitan area of Madrid and it covers a peri-urban delivery area of over $130 \mathrm{~km}^{2}$. The depot in the city center of Madrid serves a delivery area ten times smaller, around $12 \mathrm{~km}^{2}$, but with a 27 times higher density than Las Rozas.

The most important advantage of collaborating with a national logistics company is to ensure the sample is homogeneous concerning the fleet composition and socio-economic characteristics of the delivery area. In both cases, the vehicle fleet was composed of diesel and electric LDV of the same model. Figure 1 shows the geographical location of the depots involved in the field test with their corresponding delivery areas.

\subsection{The Field Trial}

The data collection campaign took place for four weeks (between 17 September 2018 and 19 October 2018). In total, 13 professional drivers (11 males and 2 females, aged between 33 and 62, with an average age of 28.6 years of driving experience) were involved in the field test. They drove electric and diesel LDV along their normal working routes, while GPS position, speed, and other parameters were collected on a second-by-second basis. For this, an OBD-II key was pre-installed in each diagnostic port of the diesel vehicles to read the data from the vehicle engine, while the MyTracks App was used for the electric LDV. In both cases, data were collected in a data logger and sampled at a frequency of $1 \mathrm{~Hz}$. 


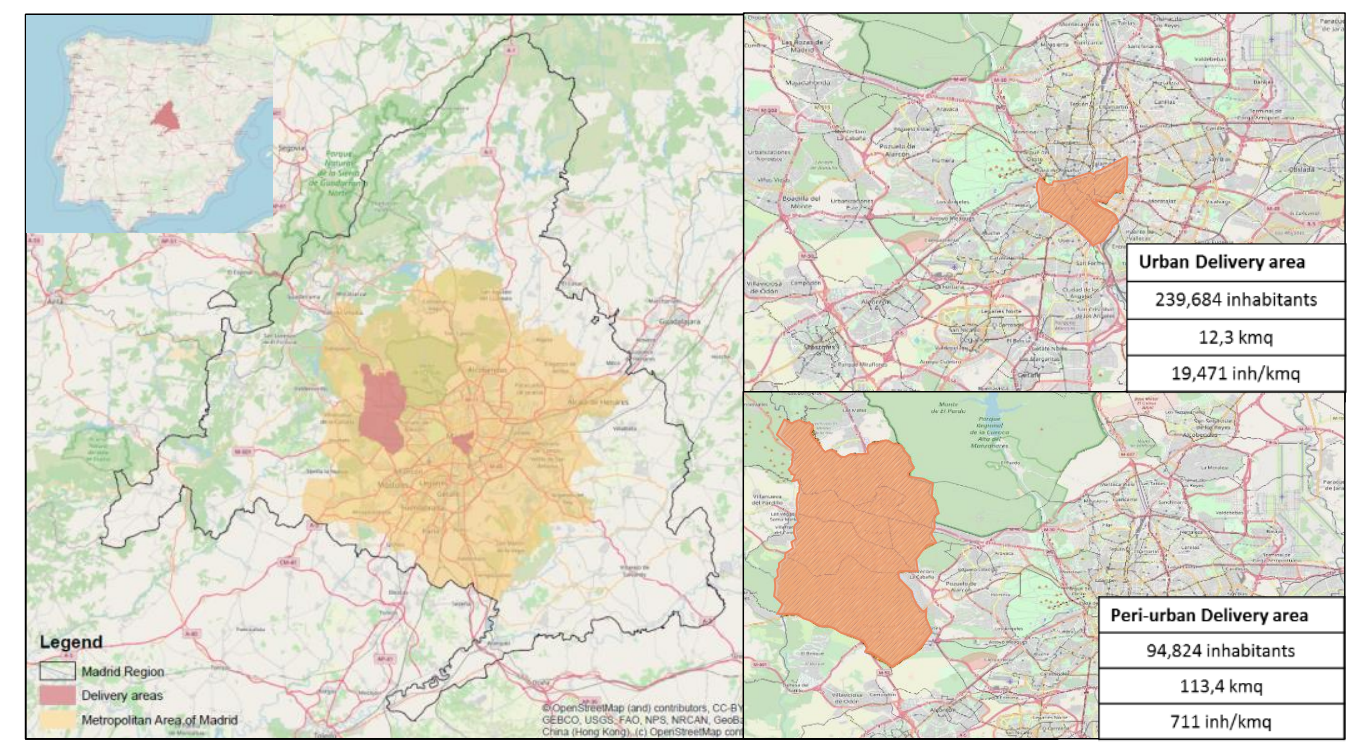

Figure 1. The Madrid metropolitan area and the field test delivery areas: city center and peri-urban.

In total, 242 delivery routes of approximately four driving hours each were recorded, covering $7262 \mathrm{~km}$. A systematic data processing approach was then used to integrate, filter, and process all the data recorded, bearing in mind that a delivery route is composed of multiple trips with different characteristics and operating conditions. Thus, for the analysis of the results, the dataset was defined in two different dimensions: first, delivery routes, to describe the main aspects of last-mile postal deliveries in terms of general operating features; and second, single parcel delivery micro-trips, to characterize driving patterns and to compare the vehicle energy efficiency while delivering in different urban contexts. Each micro-trip refers to a single delivery, and between two subsequent micro-trips a driver must park the vehicle, stop the engine, deliver the parcel, switch on the motor, and run the vehicle again until the next delivery stop (Figure 2).

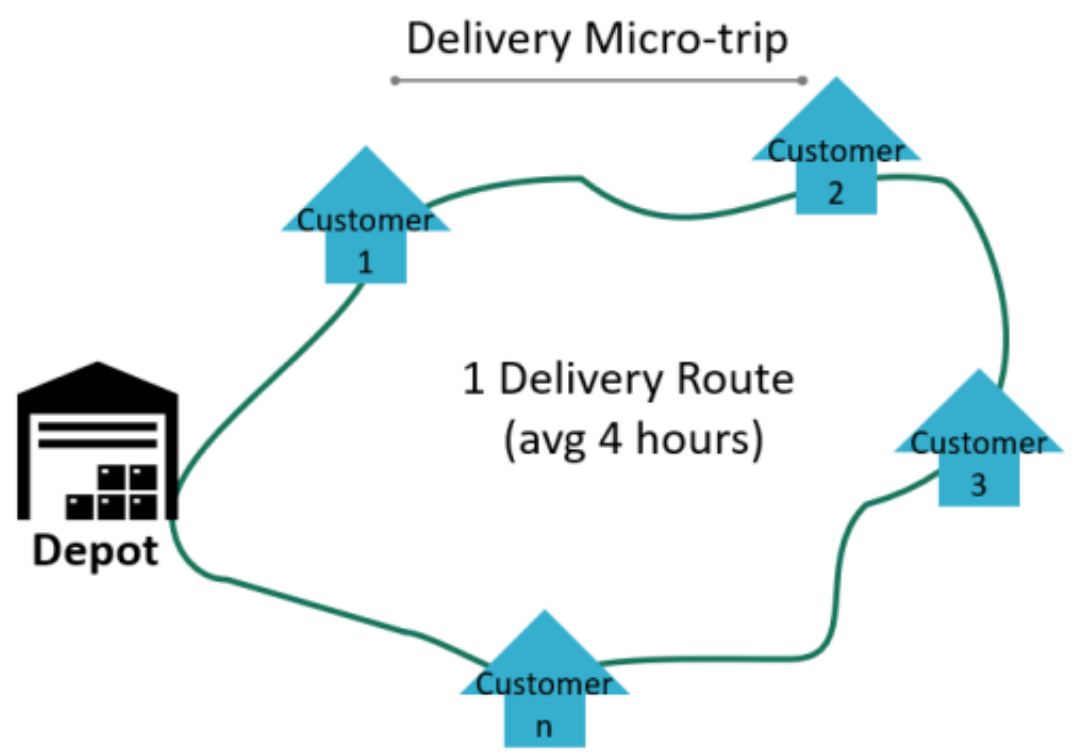

Figure 2. The schematic concept of delivery route and delivery micro-trip.

During the field trial, the routes were not predefined. The drivers individually designed their delivery route to optimize delivery times according to their experience. Therefore, each single parcel delivery micro-trip was defined daily, although the entire delivery route was similar on a day-by-day basis as each driver is assigned to a certain delivery 
micro-zone. Indeed, a common practice in large distribution companies is to allocate "micro-delivery zones" among their carriers. This is performed in an equitable manner, so that all drivers have a similar volume of work, as well as a good knowledge of the area and the requirements their main customers have.

Each single day of the experiment comprised two delivery shifts, one in the morning and one in the afternoon. The drivers completed their delivery routes during one of the two periods. Data were collected continuously from very early in the morning to late in the evening. This provided a large enough data sample to accommodate different traffic conditions and to prevent alterations in driving styles due to external circumstances.

The LDV fleet of the field test was made up of three electric Renault Kangoos and five diesel Volkswagen Transporters (both vehicle brands are used by the company nationwide) and had a EURO 6 label. In total, eight LDV were monitored during the data collection campaign-four were responsible for the delivery area in the city center and the other two for the peri-urban area. In this study, to estimate energy efficiency and pollutant emissions, only diesel LDV are considered which carried out 121 delivery routes during the data collection campaign.

\subsection{Delivery Routes Selection in City Center and Peri-Urban Area}

As shown in Figure 1, two different depot locations were chosen for collecting data for different types of delivery routes according to the built-up environment: city center and peri-urban area, with different demographic densities each, delivery distances, and running speeds. The data collected for both locations show very different operational values. Despite having similar travel times ( $4 \mathrm{~h}$ on average), in the city center, the average distance covered during a delivery route was 3.5 times lower than in the peri-urban delivery area [36]. Therefore, to perform the data analysis delivery routes were grouped according to depot location.

Although routes corresponding to the same depot had similar characteristics, and the delivery route for each specific driver was quite similar every day, certain operational features may change considerably within the same area depending on the end point of delivery. This has great influence on the energy efficiency of the vehicle, as well as on fuel consumption and pollutant emissions.

The city center area is mainly composed of local roads characterized by $30 \mathrm{~km} / \mathrm{h}$ speed limits and a few wider avenues connecting neighborhoods with $50 \mathrm{~km} / \mathrm{h}$ speed limits. On the other hand, the peri-urban area is characterized by a mixed road network, with local roads, residential areas, wide avenues, and motorways connecting neighboring villages. Therefore, within that area speed limits may vary from $30 \mathrm{~km} / \mathrm{h}$ to $120 \mathrm{~km} / \mathrm{h}$ according to the road travelled.

Out of the 138 delivery routes carried out in the city center, 80 were made almost entirely along local streets and others along mixed road sections consisting of local streets and urban avenues. Out of the 104 delivery routes travelled in the peri-urban delivery area, 50 covered residential areas of neighboring villages, which are mostly characterized by large avenues, urban arterial, and local streets. Thus, for each depot area two representative delivery routes were selected for the analysis. One route for each category was chosen in order to evaluate which delivery route was the most energy efficient and to optimize LMD operations. The following routes were selected: Route A (mixed road typologies) and Route B (mostly local roads) in the city center; Route C (mixed road typologies) and Route $\mathrm{D}$ (covering residential areas) in the peri-urban delivery area. The geolocation of the delivery route selected is shown in Figure 3. 

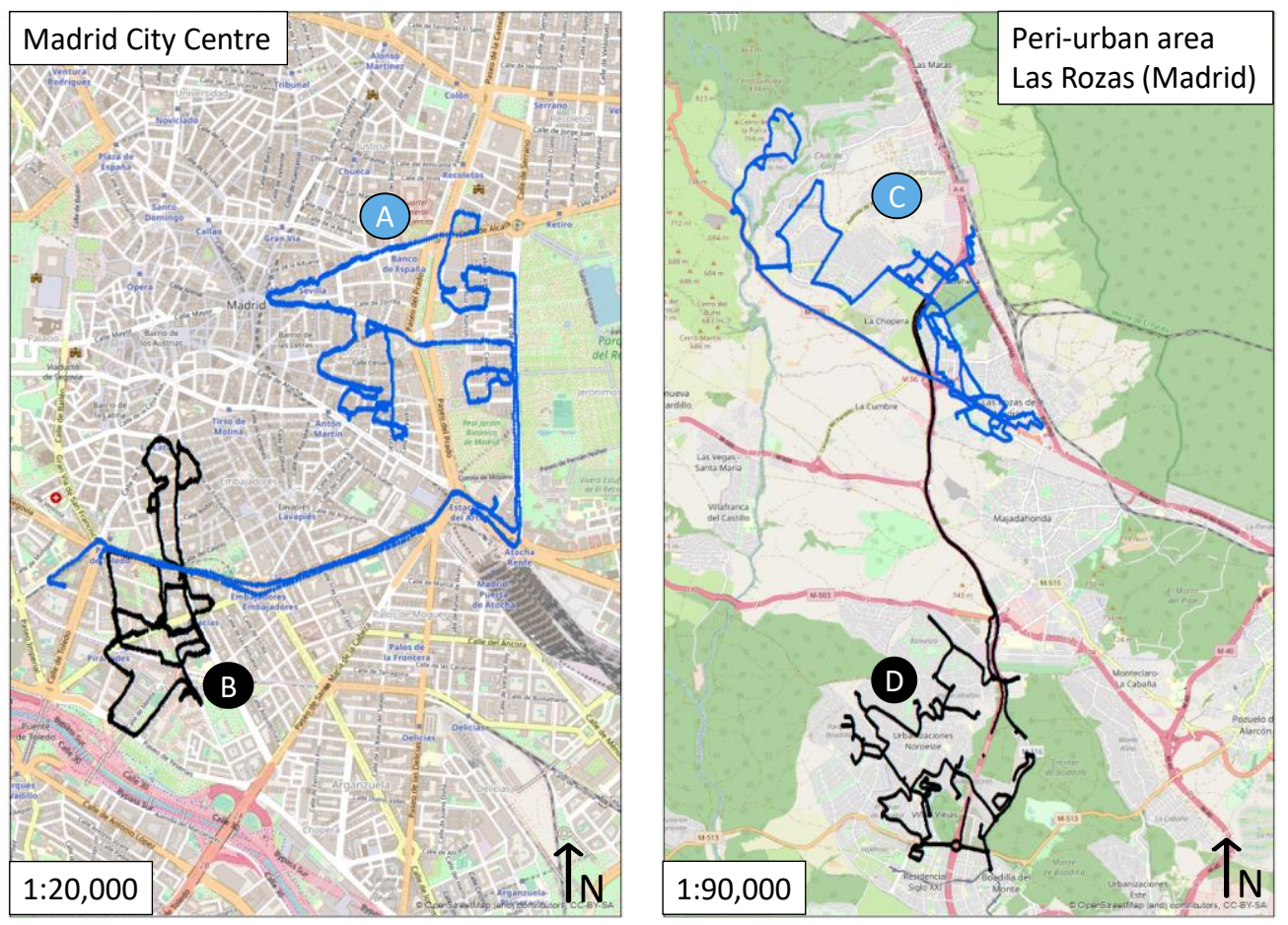

Figure 3. Geolocation of the delivery routes of the two depots: urban and peri-urban.

Groups of delivery routes corresponding to the city center depot (Madrid city):

- City center-Route A: This is a "mixed" delivery route inside the city center delivery area. Spanning $11.1 \mathrm{~km}$, the route covers an area of $3.66 \mathrm{~km}^{2}$ and is composed of both local roads and large multi-lane boulevards. In fact, it starts with the vehicle travelling from the depot through large and busy boulevards with $50 \mathrm{~km} / \mathrm{h}$ speed limits passing by two main landmarks of the city: Atocha Station and Retiro Park. Then, the driver enters the Low Emission Zone of the city center, characterized by small one-way streets with speed limits under $30 \mathrm{~km} / \mathrm{h}$. Route A represents $24 \%$ of the total sample.

- City Center-Route B: This route is almost entirely made up of small one-way local roads. Within the city center delivery area, this route has a total length of $5.6 \mathrm{~km}$, and covers an area of only $1.22 \mathrm{~km}^{2}$. There is no point along the route that is further than $1.3 \mathrm{~km}$ from the depot. The itinerary covers locations with a certain slope characterized by speed limits below $30 \mathrm{~km} / \mathrm{h}$. Route B represents $33 \%$ of the total sample.

Groups of delivery routes corresponding to the peri-urban depot (Las Rozas):

- Peri-urban-Route C: The route is a typical peri-urban 'mixed' route, crossing different types of road sections. Indeed, starting from the depot, drivers travel along local roads, cross urban arterials and get to the motorway to reach another point. Thus, they must adapt their driving behavior to the different types of roads crossed. The route is $62.1 \mathrm{~km}$ long, covers an area of $34.3 \mathrm{~km}^{2}$ and arrives at industrial estates where the vehicle might remain stationary for 30 to $90 \mathrm{~min}$. Route C represents $22 \%$ of the total sample.

- Peri-urban-Route D: This route covers a residential area and is another type of typical peri-urban delivery route. Yet, before getting there, the driver must cross a rather long stretch of motorway (characterized by a speed limit of $120 \mathrm{~km} / \mathrm{h}$ ) to make deliveries to the neighboring village. Here, the road sections are urban, characterized by avenues crossing residential areas, with little traffic and easy roadside parking. In total, the route is $47.7 \mathrm{~km}$ long and covers an area of $45.5 \mathrm{~km}^{2}$. Route D represents $21 \%$ of the total sample. 


\section{Energy Consumption and Emission Modelling}

As described in Section 3.1, during the field-test five diesel LDV were equipped with an OBD device connected to the EOBD port linked to a GPS receiver. All data were instantaneously recorded on a smart phone. Every second $i$ the following data were recorded:

- $\quad$ GPS location: longitude(long) $)_{i}$ and latitude $(\text { lat })_{i}$

- $\quad$ Running speed: $V_{i}(\mathrm{~km} / \mathrm{h})$

- $\quad$ Altitude above sea level: $h_{i}(\mathrm{~m})$

- $\quad$ Engine speed: (rpm).

However, the on-board instrumentation during the field test did not provide data on instantaneous fuel consumption, so accurate consumption and emissions according to each micro-trip were calculated at another time [37]. Therefore, a mixed-method mathematical model was designed and then experimentally validated.

The first step was to calculate the instantaneous power required to achieve the kinematic response for the vehicle being measured [38]. It is known that at each step during the test the tractive force shall be such that it counteracts total driving resistance and causes the vehicle to accelerate as required. Thus, total drag resistance at each time $\left(R_{T_{-} i}\right)$ can be calculated with the expression [39]:

$$
R_{T_{-} i}=f_{0}+f_{1} \cdot V_{i}+f_{2} \cdot V_{i}^{2}+R_{g_{-} i}
$$

where $f_{0}, f_{1}$ and $f_{2}$ are adjustment parameters for flat rolling resistance obtained from a Coast-down test that was tailor-made for the vehicle; and $R_{g_{-} i}$ is the resistance of the vehicle due to the gradient at step (i). The last can be obtained from the GPS positioning (longitude and latitude) of the vehicle and validated by means of a GIS (Geographic Information System).

Once the value for the mechanical power for each sampling time was obtained, the VSP (Vehicle Specific Power) and energy consumption could be calculated. The VSP concept was introduced in 1999 by [40] to quantify the consumption and emissions from a vehicle, and it has been used in the motor vehicle emission simulator-MOVES modeland has been updated to estimate fuel consumption and emissions. $V S P_{i}$ can be calculated by the expression:

$$
\operatorname{VSP}_{i}\left[\frac{\mathrm{W}}{\mathrm{kg}}\right]=\frac{P_{i}}{M}=V_{i}\left(1.1 \cdot a_{i}+9.81 \cdot \operatorname{grade}_{i}(\%)+0.132\right)+3.02 \cdot 10^{-4} \cdot V_{i}^{3}
$$

The methodology for assessing VSP is described in EPA [41]. Each vehicle must be characterized by specific parameters that identify its passive drag losses. For a given vehicle, they must be determined by empirical testing. To analyze emissions and consumption of European vehicles, the EEA (European Environment Agency) carried out several studies and published a guide for emissions assessment [42], which is the basis for vehicle emissions calculators such as COPERT5, developed by EMISIA [43]. In 2020, the emissions catalogue was updated [42], and according to this methodology, different tiers were established. In the current application, the Tier 1 method is of interest, and the expression for estimating exhaust emissions uses the following formula:

$$
\text { Emission }=\text { FC } \cdot \text { EF }
$$

where FC is the fuel consumption of the vehicle $(\mathrm{kg})$ and EF the fuel consumption-specific emissions factor which can be derived from the vehicles used in the field test. The emissions factors for the LDV used in the experiment are shown in Table 1. 
Table 1. Emissions factors for light commercial diesel vehicles [34].

\begin{tabular}{ccccccc}
\hline $\mathbf{( k g / k g}$ Fuel) & \multicolumn{7}{c}{ (g/kg Fuel) } \\
\hline $\mathbf{C O}_{\mathbf{2}}$ & $\mathrm{CO}$ & NMVOC & $\mathbf{N O}_{\mathbf{x}}$ & $\mathbf{P M}$ & $\mathbf{N}_{\mathbf{2}} \mathbf{O}$ & $\mathbf{N H}_{\mathbf{3}}$ \\
\hline 3.169 & 7.40 & 1.54 & 14.91 & 1.52 & 0.056 & 0.038 \\
\hline
\end{tabular}

The energy consumed on a delivery micro-trip of a known duration can be calculated by evaluating the power required for that particular micro-trip. Additionally, according to EMEP/EEA [42], the value for density and the calorific value for diesel fuel is assumed to be $840 \mathrm{~kg} / \mathrm{m}^{3}$ and $42.695 \mathrm{MJ} / \mathrm{kg}$ respectively. Then, energy efficiency can be obtained from the energy corresponding to the fuel consumed in relation to the effective mechanical tractive energy obtained from the vehicle dynamics.

Calibration entails monitoring the consumption under controlled driving conditions, and this should be performed in specific trials. This calibration phase is specific to each vehicle, and it enables both the characteristic parameters of drag resistances $\left(f_{0}, f_{1}\right.$ and $f_{2}$ ) and the consumption/energy ratio to be obtained. In order to identify the parameters for expressing drag resistance, Coast-down tests were carried out (see Section 4.1). The Coast-down test consists of launching a motor vehicle from a given speed with the engine disengaged and recording the speed and time during free rolling until the vehicle stops. This procedure allows the determination of the running resistance (aerodynamics, rolling resistance, etc.). The latest version of European Regulation 2017/1151 [44] includes Coastdown tests. The procedure is defined for evaluating resistance in the $20-130 \mathrm{~km} / \mathrm{h}$ range.

\subsection{Calibration Test}

The calibration test was performed with the Free Deceleration Method with stationary anemometry according to EU Regulation 2017/1151. The free deceleration time for each reference speed $V_{i}$ was measured which corresponds to the time elapsed between vehicle speeds $\left(V_{i}-5 \mathrm{~km} / \mathrm{h}\right)$ and $\left(V_{i}+5 \mathrm{~km} / \mathrm{h}\right)$.

For the experimental trial, an LDV Volkswagen Transporter with exactly the same characteristics, dimensions, and functionality as the diesel vehicles used during the main data collection campaign was equipped with the following instrumentation:

- $\quad$ GPS Racelogic high frequency differential receiver $(100 \mathrm{~Hz})$, model VBox3 + RTK for centimetric accuracy.

- $\quad$ Inertial Measurement Unit (IMU) ADMAg

- Dewetron recording equipment.

- Connectors for reading data via the OBD port.

The main characteristics of the vehicles are shown in Table 2 below.

Table 2. Experimental trial vehicle information.

\begin{tabular}{cc}
\hline Vehicle Model: & Volkswagen Transporter \\
\hline Type & $\mathrm{N} 1$ \\
Bodywork & $\mathrm{BB}$ \\
Mass in running order & $1890 \mathrm{~kg}$ \\
Maximum Mass & $2800 \mathrm{~kg}$ \\
Length & $4904 \mathrm{~mm}$ \\
Overall width & $1904 \mathrm{~mm}$ \\
Height & $1970 \mathrm{~mm}$ \\
Tires & $205 / 65 \mathrm{R} 16 \mathrm{C} 107 / 105 \mathrm{~T}$ \\
Engine & $167 \mathrm{~g} / \mathrm{km}$ \\
CO emissions $_{2}$, inline 4 -cylinder, $81 \mathrm{~kW}$ \\
Noise level at standstill & $76 \mathrm{~dB}$ \\
Emission level & EURO 6CI \\
Noise level at standstill & $76 \mathrm{~dB}$ \\
Emission level & EURO 6CI
\end{tabular}


The measurements of free deceleration time were made in opposite directions until at least three pairs of measurements met the statistical accuracy required [44], and the test interval was carried out, considering the speed limits within which the vehicle was tested, $[20,100] \mathrm{km} / \mathrm{h}$.

This program was developed for three types of journeys: urban $(V<50 \mathrm{~km} / \mathrm{h})$, rural + conventional road, and motorway $(V>90 \mathrm{~km} / \mathrm{h})$.

The experimental program consisted of a set of journeys at different initial speeds, between 20 and $100 \mathrm{~km} / \mathrm{h}$. By means of Coast-down tests, stopping accelerations were obtained at intervals of $10 \mathrm{~km} / \mathrm{h}$ drops in speed. These runs were carried out on flat road sections. In order to extend the model to roads with slopes resistance, measurements were carried out on sections with constant slopes. A total of $215 \mathrm{~km}$ was covered in developing these passive resistance characterization tests.

Through these experimental trials representative values for the energy consumed and the fuel consumption for the specific vehicle were obtained.

The rolling resistance equation has the following formula:

$$
F=f_{0}+f_{1} \cdot V_{i}+f_{2} \cdot V_{i}^{2}
$$

where $f_{0}=[\mathrm{N}] ; f_{1}=[\mathrm{N} /(\mathrm{km} / \mathrm{h})] ; f_{2}=\left[\mathrm{N} /(\mathrm{km} / \mathrm{h})^{2}\right]$.

After carrying out the experimental trial and processing the data, an expression for flat forward resistance $(F)$ was obtained with a regression value of $\mathrm{R}^{2}=0.98$. According to EU Regulation 2017/1151 (Annex XXI, sub annex 4) [44], the final expression is:

$$
F=151.5+1.008 \cdot V_{i}+0.05378 \cdot V_{i}^{2}
$$

Once the resistance was characterized from speed, acceleration, and ramp measurements, the mechanical energy required to perform each micro-trip was obtained. A model was developed to correlate mechanical energy with fuel consumption. This was based on implementing a second experimental program in which fuel consumption and vehicle (trajectory, speed, acceleration, engine speed) as well as road (ramp) variables were monitored. Urban, rural, motorway and mixed routes were covered over a total of $320 \mathrm{~km}$ travelled. As a result, a relationship between energy consumed $(\mathrm{kW} \cdot \mathrm{h})$ and fuel consumption could be obtained (L).

Figure 4 shows the results of the calibration test for the equipped VW Transporter, which provided the consumption/energy ratio as a function of speed.

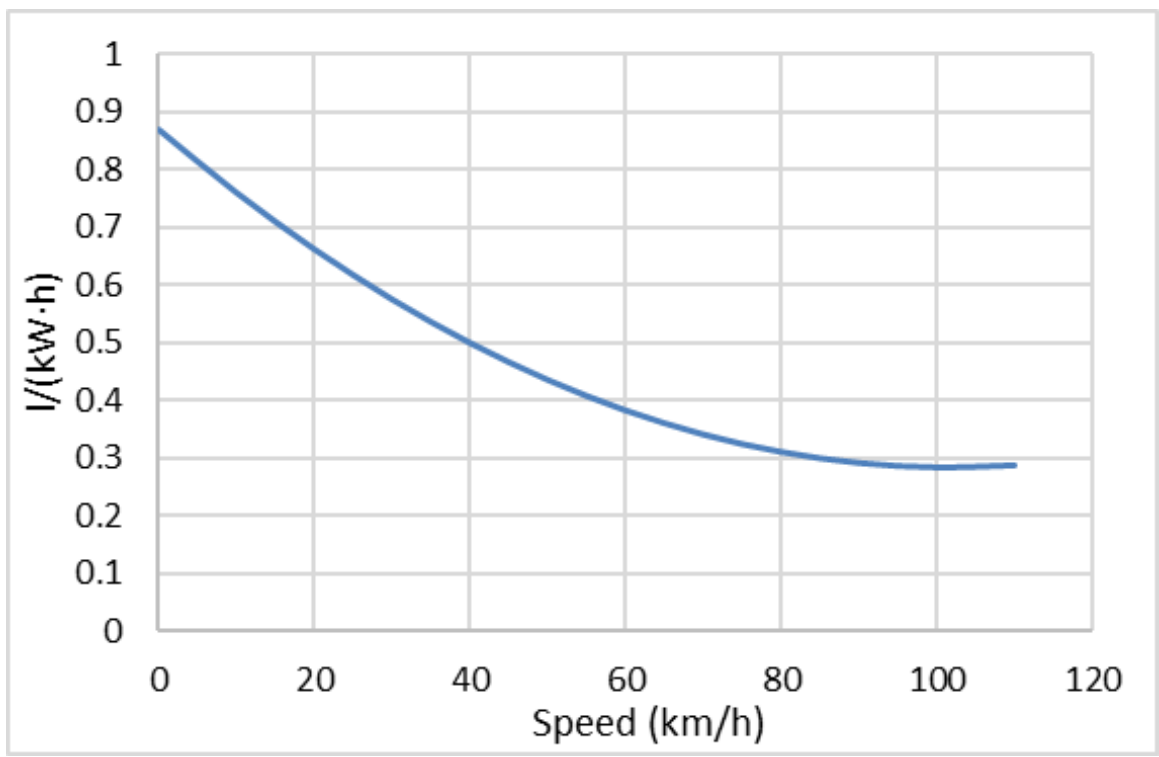

Figure 4. Fuel consumption/Energy ratio. 
This ratio is expressed as:

$R_{c_{\_} E}[\mathrm{~L} / \mathrm{kWh}]=0.0000565660626809469 \cdot V^{2}-0.0115230586305416 \cdot V+0.870459094964598$

where $V$ represents the average speed of the micro-trip studied.

Once the accurate ratio of the vehicle used in the experiment was obtained, Formula (6) was applied to all the micro-trips recorded during the field test in the two depots of the case study.

Using the model relating mechanical energy and consumption, we then analyzed the data obtained from the field tests carried out with the postal vehicles. To do so, the values of speed, acceleration, and ramp at each instant were taken as a starting point and the mechanical power $(\mathrm{kW})$ was determined. For each micro-trip, the total mechanical energy $(\mathrm{kW}-\mathrm{h})$ was quantified. With the ratio (6), the consumption proper of each micro-trip was obtained on the basis of this and by applying Table 1, the values for the gaseous emissions for each trip were obtained.

\section{Analysis of Results: Energy Efficiency in LMD}

This chapter forms the analysis of the results of this study following two data sets created. These refer to multiple-trip delivery routes and single parcel delivery micro-trips.

\subsection{Operative Features Proper for Different Multiple-Trip Delivery Routes: City Center and Peri-Urban Area}

For analyzing differences in energy efficiency and pollutant emissions in LMD, we first defined the operative features of each of the four types of delivery routes considered in the study. The next Figures 5 and 6 show the routes selected for the analysis, the geolocation, and the instantaneous speed of the driver while making deliveries along each route. Considering their characteristics (Section 3.2), the main operational features are analyzed, which directly influence the energy efficiency of the vehicle, as well as the fuel consumption and pollutant emissions.
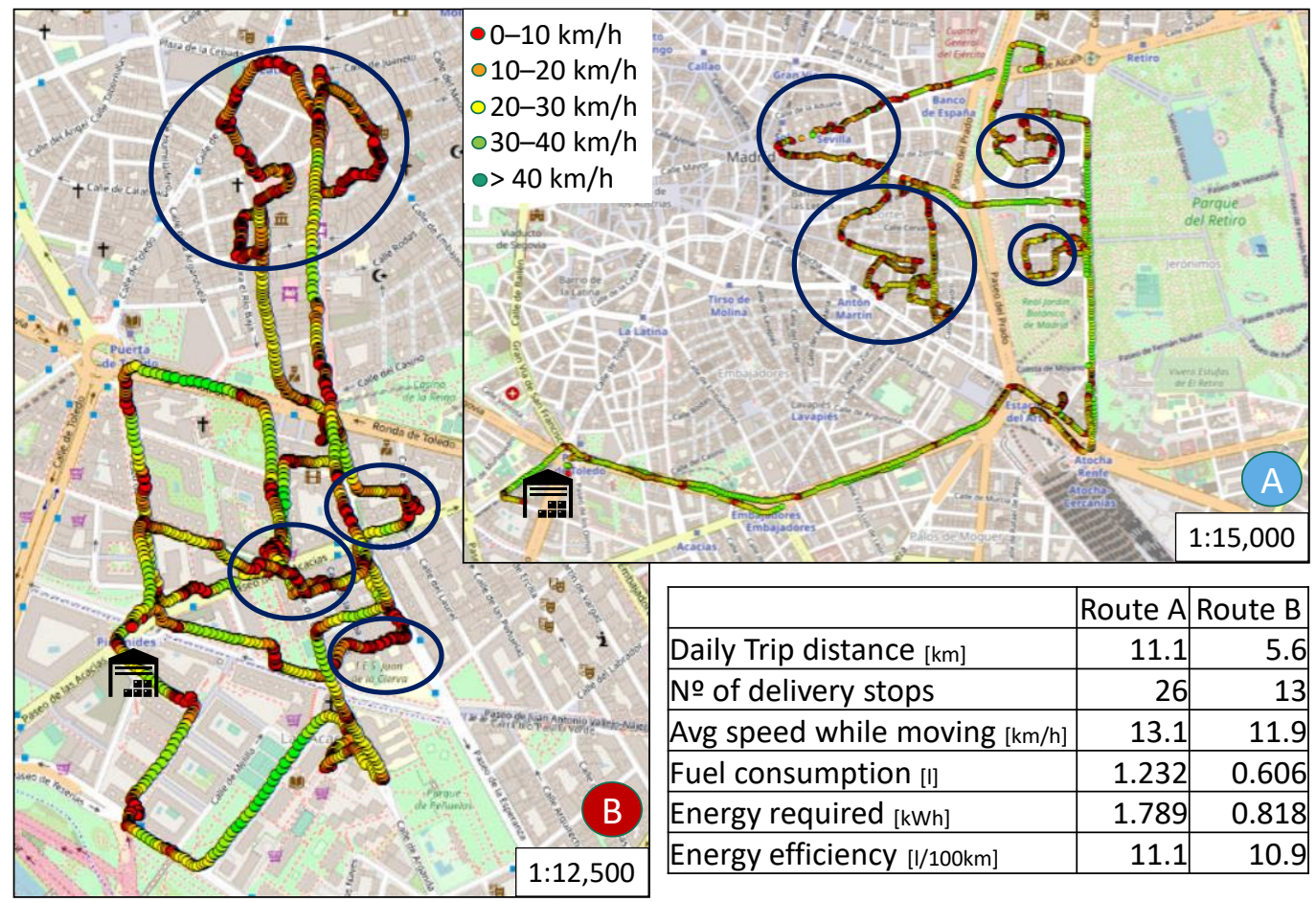

Figure 5. Geolocation and instantaneous speed of the delivery routes in Madrid city center. 


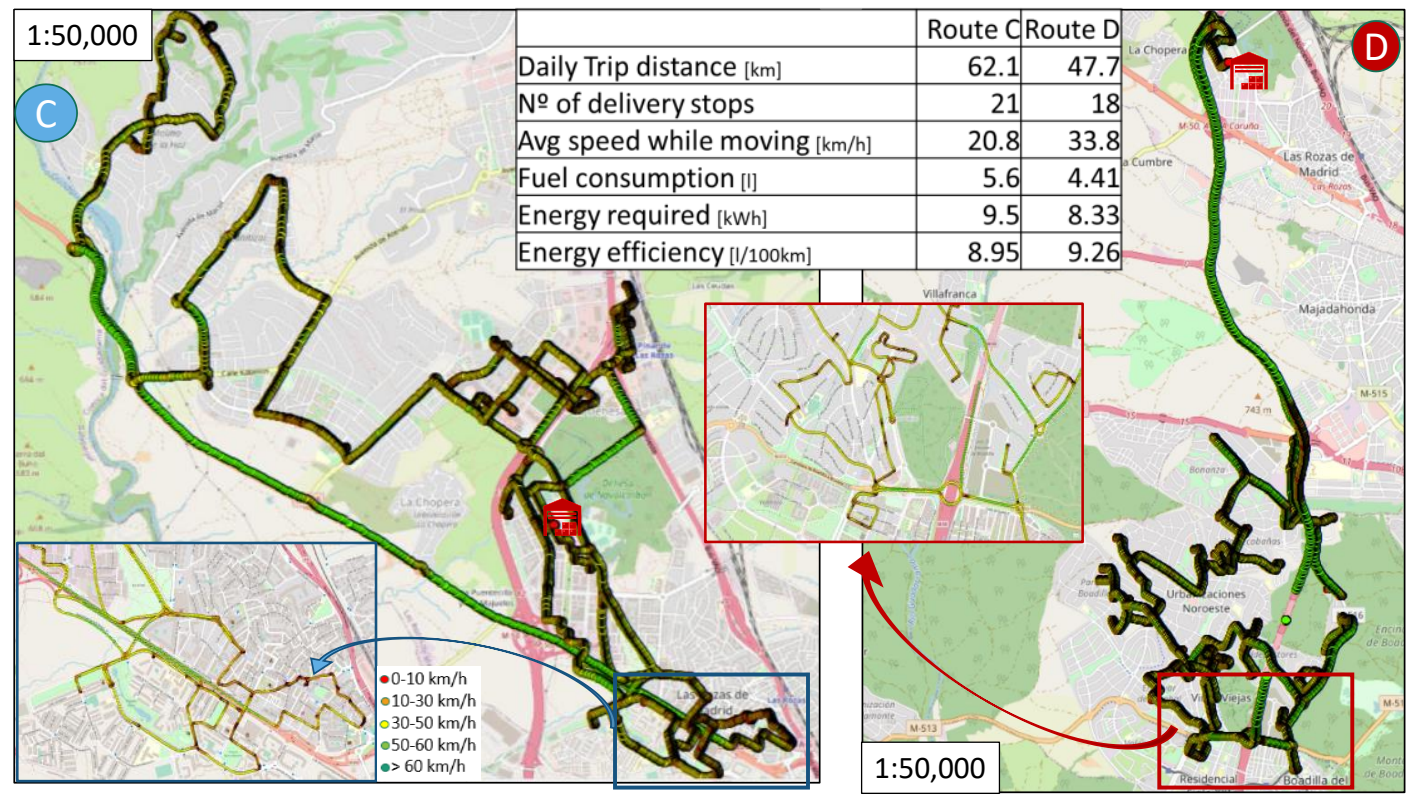

Figure 6. Geolocation and instantaneous speed of delivery routes in the peri-urban area of Madrid.

- Delivery routes corresponding to the city center depot (Madrid city):

The city center of Madrid is composed of local and urban roads, characterized by $30 \mathrm{~km} / \mathrm{h}$ and $50 \mathrm{~km} / \mathrm{h}$ speed limits; the same area is highly congested and usually shows a lack of parking spaces. The whole delivery routes take approximately $4 \mathrm{~h}$. However, they are rather short in terms of distances: $11.1 \mathrm{~km}$ for Route A and $5.6 \mathrm{~km}$ for Route B. Furthermore, the subsequent delivery points are very close to each other; along Route A, the average distance between consecutive delivery stops is $420 \mathrm{~m}$, while for Route B it is $430 \mathrm{~m}$.

According to these delivery patterns, the average speed while moving is very low, $13.1 \mathrm{~km} / \mathrm{h}$ for Route A and $11.9 \mathrm{~km} / \mathrm{h}$ for Route B, as well as the energy efficiency of the vehicle is. Nevertheless, Figure 5 shows the average speed while moving but if a speed of $0 \mathrm{~km} / \mathrm{h}$ is considered, the average speed is even lower: $7 \mathrm{~km} / \mathrm{h}$ for Route $A$ and $5 \mathrm{~km} / \mathrm{h}$ for Route B. Thus, traffic lights, congestion, and pedestrian crossings reduce the average operating speed by $48 \%$ and $57 \%$, and the energy efficiency of the vehicles in turn. Figure 5 shows the instantaneous speed of the vehicle during the whole delivery route, and the colours are consistent with speed ranges. As shown, there are some micro-zones where operating speeds always remain under $10 \mathrm{~km} / \mathrm{h}$. Additionally, $40 \%$ of the sample has an average speed of a single parcel delivery micro-trip lower than $10 \mathrm{~km} / \mathrm{h}$, an aspect that points at reflecting on the real need for transferring LMD operations to no-motorized modes, especially in city centers.

In this area, there is an inefficient combination of short delivery distances with traffic congestion and less effective service. At lower speeds, the engine is less efficient and consequently, the vehicle consumes more fuel and increases pollutant emissions. Moreover, being characterized by very short single parcel delivery micro-trips, the acceleration and braking time are significant in relation to travel time. This is known to have a direct impact on fuel consumption and pollutant emissions [45].

Therefore, deliveries along these types of multiple-trip delivery routes are quite inefficient and produce a large number of externalities, regardless of the delivery route typology. Indeed, the results show that energy efficiency is more influenced by the geographical context (city center) than by the road network (route A or B): despite the differences among delivery routes (Section 3.2), the energy efficiency of the LDV remains practically the same, being only $2 \%$ better in the case of Route B. 
- Delivery routes corresponding to the peri-urban depot (Las Rozas, Madrid):

The peri-urban case is completely different in terms of operating features. Figure 6 shows the instantaneous positioning and proper speed for the two delivery routes selected in the peri-urban delivery area.

Just as seen in the city center, in this case the delivery routes in total take approximately $4 \mathrm{~h}$ to be completed. Nonetheless, the total length is over three times as long as those for deliveries in the city center, with $62.1 \mathrm{~km}$ for Route $C$ and 47.7 for Route D. Subsequent deliveries can be very close to each other, as in the case of Route $\mathrm{D}$ when the courier arrives to the residential area. On the contrary, they may be very far apart, as in the case of the first delivery of the day, which is usually some kilometers away from the depot and for which a rather long section of motorway has to be crossed. In these terms, the average distance between subsequent delivery stops increases up to $2.95 \mathrm{~km}$ along Route C, and $2.65 \mathrm{~km}$ along Route D. In the peri-urban delivery area, drivers spend an average of $67 \%$ on local streets, $23 \%$ on urban arterials, and $10 \%$ on motorways, which connect one residential community with another. It was observed that during peri-urban multiple-trip delivery routes, drivers crossed completely different road sections to complete their delivery routes and they had to adapt their driving behaviors to different road contexts while making a single delivery.

As shown in Route D, for example, the driver leaves the depot and takes the motorway to the next community. This implies switching from speed limits above $100 \mathrm{~km} / \mathrm{h}$ to a speed limit of $30 \mathrm{~km} / \mathrm{h}$. Consequently, the average speed in transit is higher than the one in the city center, and the vehicles are more energy efficient. Indeed, the average speed in transit is $20.8 \mathrm{~km} / \mathrm{h}$ along Route $\mathrm{C}$ and $33.8 \mathrm{~km} / \mathrm{h}$ along Route $\mathrm{D}$. These fall to $12 \mathrm{~km} / \mathrm{h}$ and $17 \mathrm{~km} / \mathrm{h}$ respectively if the speed of $0 \mathrm{~km} / \mathrm{h}$ is considered $(42 \%$ and $49 \%$ lower, respectively).

As shown in Figure 6, there are some micro-zones within which the drivers drastically reduce their speed, but unlike in the city center, here, there are no zones in which the average speed falls below $10 \mathrm{~km} / \mathrm{h}$. In fact, peri-urban areas are generally characterized by wide avenues where drivers can easily stop their vehicles to make a delivery without reducing drastically their average speed to look for a parking space. Normally, periurban areas are not congested except on motorway intersections or at particular points (e.g., entrances to busy roundabouts). Drivers usually know their delivery areas and are aware of critical passages. As a result, the operating speed of the vehicle in the peri-urban area is in average $30 \mathrm{~km} / \mathrm{h}$ which means the engine performs better and vehicles are more energy-efficient compared to city center deliveries.

On a final note, in light of the differences described in Section 3.2, the results show that Route C is 3.3\% more energy-efficient than Route D. In fact, Route D mostly crosses residential areas characterized by several pedestrian crossings which reduce the overall energy efficiency, accounting for the numerous times the driver must slow down or stop the LDV.

\subsection{Energy Efficiency and Pollutant Emissions on Last-Mile Delivery Micro-Trips}

The consumption/energy ratio in Equation (6) (Figure 4) enables vehicle energy consumption and pollutant emissions to be calculated for each micro-trip. Table 3 summarizes the average results according to the multiple-trip delivery route typology and the delivery area.

Comparing the longitude of the micro-trips, it emerges that within Route A there are single deliveries which are $60 \mathrm{~m}$ apart from each other, as well as others of up to $3 \mathrm{~km}$ apart. This means a 50-fold increase in the length of the journey when making one delivery or another. Similarly, it occurs in the peri-urban area: Routes $C$ and D account for single delivery micro-trips of $20 \mathrm{~m}$ length as well as $18.56 \mathrm{~km}$. This aspect shows the importance of differentiating optimal LMD solutions even within the same delivery area, and why a range of solutions adapted to each context is essential. For instance, within the same zone 
of the peri-urban delivery area, a bicycle may replace shorter distance deliveries. Yet, this would not be suitable for deliveries further away than $10 \mathrm{~km}$.

Table 3. Energy efficiency and pollutant emissions during last-mile delivery micro-trips.

\begin{tabular}{|c|c|c|c|c|c|c|c|c|c|c|c|c|}
\hline \multirow[b]{3}{*}{ Features } & \multicolumn{6}{|c|}{ City Center Delivery Area } & \multicolumn{6}{|c|}{ Peri-Urban Delivery Area } \\
\hline & \multicolumn{3}{|c|}{ Route A (11.1 km) } & \multicolumn{3}{|c|}{ Route B (5.6 km) } & \multicolumn{3}{|c|}{ Route C $(62.1 \mathrm{~km})$} & \multicolumn{3}{|c|}{ Route D (47.7 km) } \\
\hline & Min & Max & Avg & Min & Max & Avg & Min & Max & Avg & Min & Max & Avg \\
\hline Micro-trip distance $(\mathrm{km})$ & 0.06 & 3.79 & 0.43 & 0.12 & 1.28 & 0.43 & 0.02 & 18.56 & 2.96 & 0.17 & 10.73 & 2.75 \\
\hline Avg micro-trip speed (km/h) & 3.7 & 33.3 & 13.1 & 7.8 & 18.3 & 11.9 & 3.5 & 36.0 & 20.8 & 11.2 & 65.0 & 31.4 \\
\hline $\begin{array}{l}\text { Fuel consumption } \\
\text { (L/micro-trip) }\end{array}$ & $<0.01$ & 0.36 & 0.05 & 0.01 & 0.14 & 0.05 & 0.01 & 1.54 & 0.26 & 0.02 & 0.84 & 0.26 \\
\hline Fuel consumption (L/100 km) & 3.53 & 21.98 & 11.25 & 3.47 & 24.37 & 11.20 & 3.83 & 26.32 & 10.23 & 4.70 & 47.90 & 11.00 \\
\hline Efficiency- $\eta(\%)$ & 13.6 & 20.5 & 15.5 & 14.3 & 16.6 & 15.2 & 13.5 & 21.3 & 20.4 & 15.0 & 31.2 & 20.4 \\
\hline Energy $(\mathrm{kW} \cdot \mathrm{h} / 100 \mathrm{~km})$ & 1.8 & 31.5 & 15.5 & 4.9 & 32.0 & 15.0 & 5.3 & 31.6 & 15.3 & 7.2 & 28.2 & 15.0 \\
\hline Energy fuel (kWh/100 km) & 13.4 & 192.9 & 99.5 & 31.3 & 216.2 & 99.5 & 33.2 & 252.6 & 91.9 & 29.7 & 426.9 & 95.0 \\
\hline $\mathrm{CO}_{2}(\mathrm{~kg} / 100 \mathrm{~km})$ & 3.7 & 51.8 & 26.6 & 8.3 & 57.9 & 26.6 & 8.9 & 68.4 & 24.6 & 7.9 & 114.1 & 25.4 \\
\hline $\mathrm{CO}(\mathrm{g} / 100 \mathrm{~km})$ & 8.5 & 120.6 & 62.2 & 19.4 & 135.0 & 62.1 & 20.6 & 157.9 & 57.3 & 18.5 & 266.4 & 59.3 \\
\hline NMVOC (g/100 km) & 1.7 & 24.8 & 12.9 & 4.2 & 27.9 & 12.9 & 4.3 & 31.6 & 11.9 & 3.8 & 55.5 & 12.3 \\
\hline $\mathrm{NO}_{\mathrm{x}}(\mathrm{g} / 100 \mathrm{~km})$ & 17.1 & 242.6 & 125.1 & 38.9 & 272.1 & 125.0 & 41.7 & 315.8 & 115.4 & 37.3 & 537.8 & 119.4 \\
\hline $\mathrm{PM}(\mathrm{g} / 100 \mathrm{~km})$ & 1.7 & 24.8 & 12.7 & 4.2 & 27.9 & 12.8 & 4.3 & 31.6 & 11.7 & 3.8 & 54.8 & 12.2 \\
\hline $\mathrm{N}_{2} \mathrm{O}(\mathrm{g} / 100 \mathrm{~km})$ & $<0.1$ & 1.1 & 0.8 & $<0.1$ & 1.0 & 0.4 & $<0.1$ & 0.6 & 0.4 & 0.1 & 2.0 & 0.4 \\
\hline $\mathrm{NH}_{3}(\mathrm{~g} / 100 \mathrm{~km})$ & $<0.1$ & 0.4 & 0.3 & $<0.1$ & 0.7 & 0.3 & $<0.1$ & 0.6 & 0.3 & 0.1 & 1.4 & 0.3 \\
\hline
\end{tabular}

Not only do distances vary considerably, but also the operating speed during the journey and the engine efficiency change to a great degree. The latter has a direct effect on the fuel consumption of the vehicle and its pollutant emissions. In the city center, the overall energy efficiency fluctuates by around $15 \%$ due to the lower operating speeds typical for that area. The best efficiency is reached during a delivery micro-trip included in Route A, which is $580 \mathrm{~m}$ long and with an average speed in transit of $33.3 \mathrm{~km} / \mathrm{h}$. This results in an efficiency of $20.5 \%$. On the other hand, in the peri-urban area, efficiency fluctuates by around $20 \%$ and the optimum case corresponds to a delivery micro-trip included in Route $\mathrm{D}$, which is $10.73 \mathrm{~km}$ long and with an average speed in transit of $65 \mathrm{~km} / \mathrm{h}$. This leads to an efficiency of $32 \%$.

Of all the delivery micro-trips performed in the city center, $58 \%$ register an efficiency lower than $15 \%$; for the $37 \%$ of the sample, the efficiency is between 15 and $20 \%$, while only $5 \%$ of the sample in the city center register an efficiency greater than $20 \%$. The latter are those few micro-trips in which it is possible to maintain a higher and more homogeneous operating speed during the journey. A complete difference regarding the efficiency is shown in the case of delivery micro-trips in the peri-urban area: while only $3 \%$ of the sample does not reach $15 \%$ of efficiency, three quarters of the sample report an efficiency between 15 and $20 \%$. In general, the peri-urban delivery area leads to an efficiency of $33 \%$ higher than the one achieved in the city center. The least efficient conditions correspond with Route A, in which $50 \%$ of the micro-trips shows an efficiency lower than $14 \%$. Figure 7 illustrates the efficiency in intervals and the distribution of aggregated data according to the delivery area.

Another aspect that strongly impacts the fuel consumption and pollutant emissions for single parcel delivery micro-trips is its longitude. In fact, when the delivery micro-trip is very short, i.e., a few dozen meters, it is extremely difficult to optimize the energy efficiency of the vehicle and thus reduce pollutant emissions. Figure 8 shows the average value of fuel consumption per $\mathrm{km}$ according to the micro-trip length.

Figure 8 shows the difficulty of assigning a single energy efficiency value for very short delivery micro-trips. Indeed, along these types of journeys, a constant speed is rarely maintained as they are usually characterized by significant accelerations and decelerations during a large part of the travel time. Thus, both fuel efficiency and fuel consumption, and 
pollutant emissions, in turn, can vary greatly. In the city center, a single parcel delivery micro-trip of $150 \mathrm{~m}$ length can be responsible for a fuel consumption of 50 or $140 \mathrm{~mL} / \mathrm{km}$. This means eventually almost the tripled for the same distance. As presented in Section 5.1, the operating speed in the city center is mostly very low; thus, from these values we can deduce the important role acceleration has on fuel consumption for very short delivery micro-trips. This refers to the impact that congestion, traffic lights, and intersections have on reducing the efficiency of LDV while delivering in city center. The influence of acceleration decreases when the longitude of the micro-trip increases. According to this, Figure 8 shows that the fuel consumption per $\mathrm{km}$ tends to be constant when the distance travelled increases.

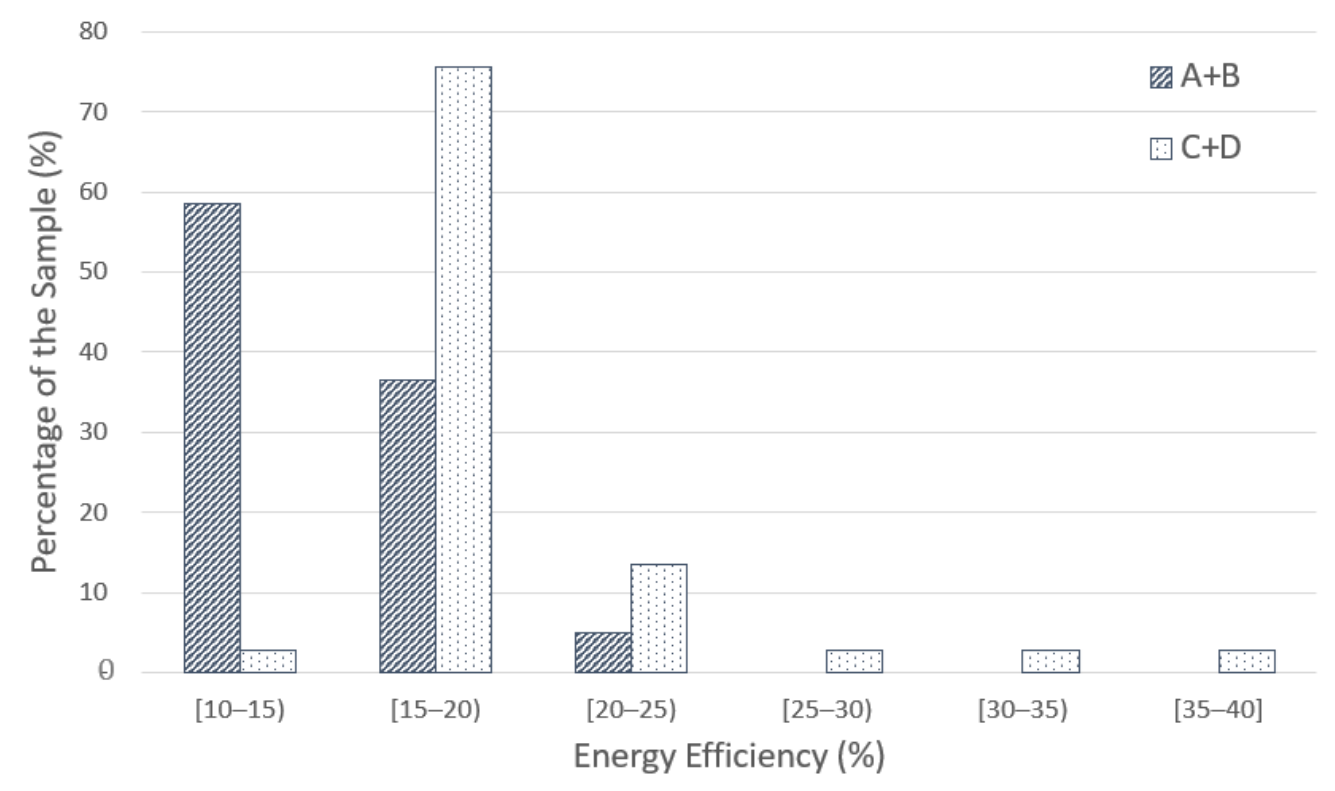

Figure 7. Comparison between energy efficiency proper for delivery micro-trips in the city center $(A+B)$ or peri-urban $(C+D)$ delivery area.

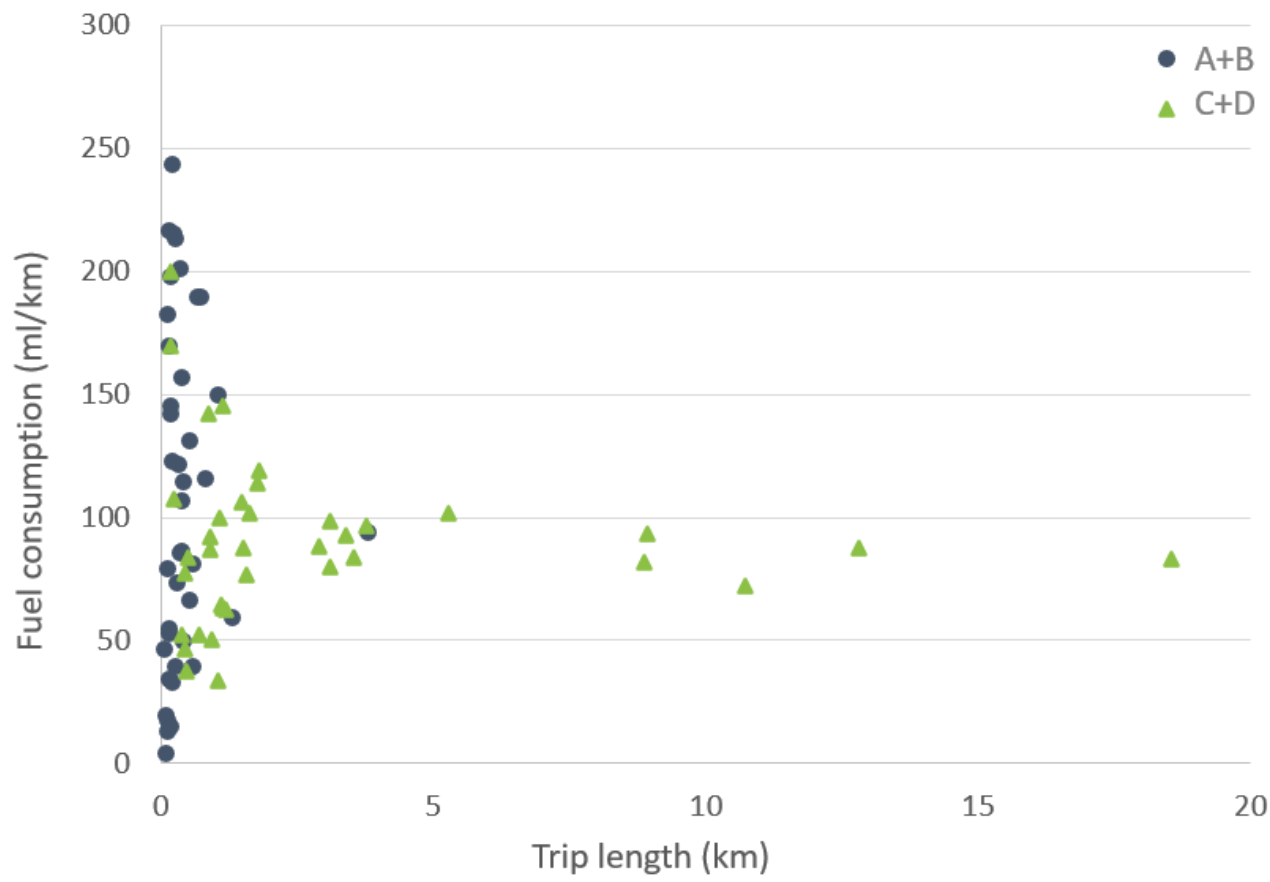

Figure 8. Comparison between fuel consumption for delivery micro-trips in the city center $(A+B)$ or peri-urban $(C+D)$ delivery area. 
Pollutant emissions in LMD follow the same trend of fuel consumption which means that they have a great variability for short trips and tend to have a constant value as the longitude of the journey increases. Indeed, considering two different delivery micro-trips carried out by the same LDV and driver, $\mathrm{CO}_{2}$ emissions vary from $35.9 \mathrm{~g} / \mathrm{km}$ to $515.7 \mathrm{~g} / \mathrm{km}$ even if average speed was around $9 \mathrm{~km} / \mathrm{h}$ for both micro-trips and deliveries were performed in the same area in the city center. On the other hand, in the peri-urban delivery area for both shorter and longer micro-trips (ranging from $3 \mathrm{~km}$ to $15 \mathrm{~km}$ longitude), the average value of $\mathrm{CO}_{2}$ emissions is around $200 \mathrm{~g} / \mathrm{km}$ (Figure 9).

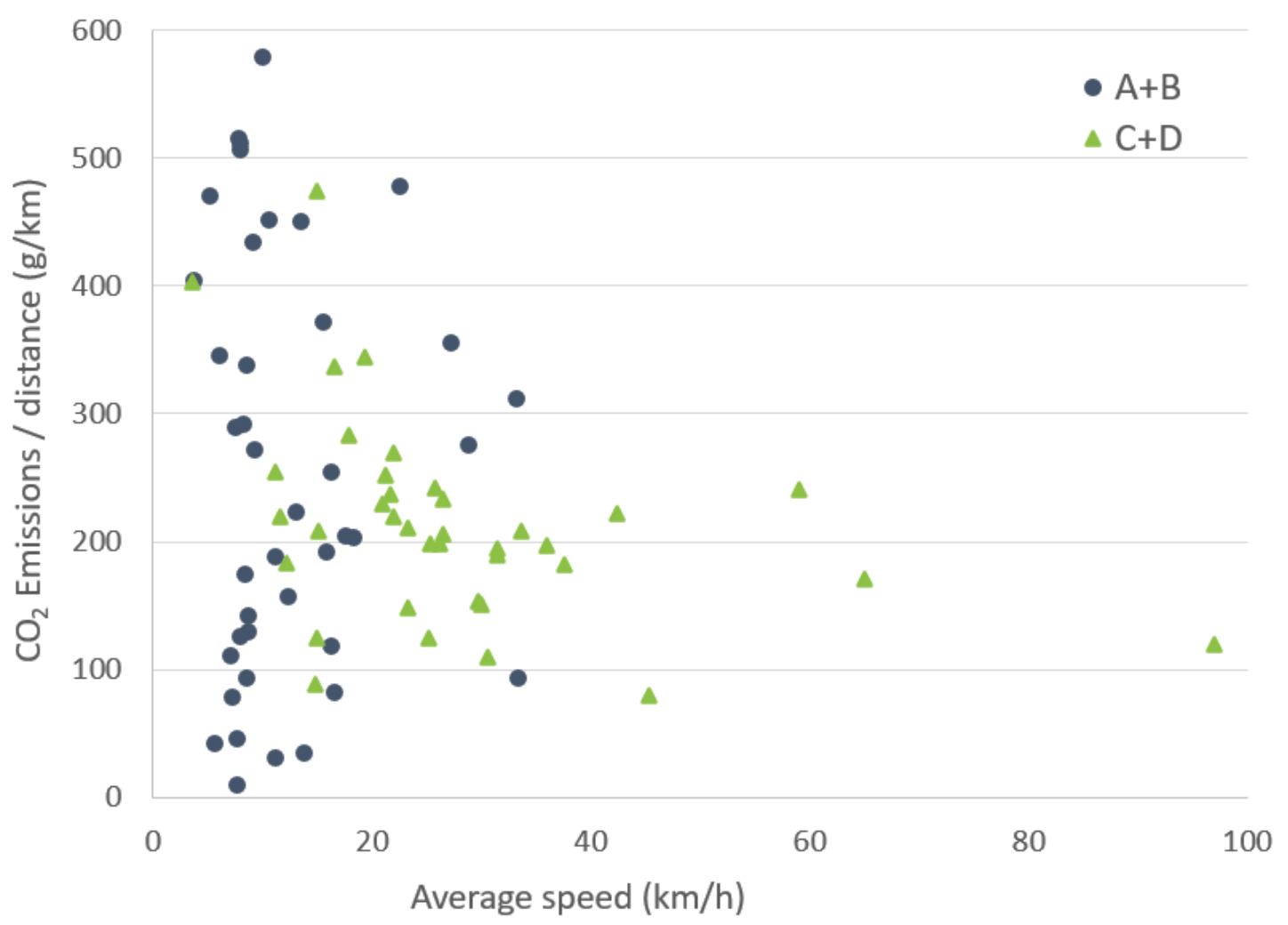

Figure 9. Comparison between $\mathrm{CO}_{2}$ emissions per $\mathrm{km}$ travelled as function of the average speed in the city center $(\mathrm{A}+\mathrm{B})$ and Peri-urban $(\mathrm{C}+\mathrm{D})$ delivery area.

Figure 9 shows the high variability of $\mathrm{CO}_{2}$ emissions per $\mathrm{km}$ at lower operative average speeds which are mainly referring to the city center context. Comparing both optimal cases for each delivery area, it may be concluded that pollutant emissions per $\mathrm{km}$ driven are significantly lower in the peri-urban area: $15.9 \%$ less $\mathrm{CO}_{2}$ emissions, $16.7 \%$ less $\mathrm{CO}$ emissions, and $18 \%$ less $\mathrm{NO}_{\mathrm{x}}$ emissions in average. Even though fuel consumption per micro-trip is lower in the city center due to shorter delivery distances, the energy efficiency for LMD in the peri-urban area is considerably higher. In fact, the higher the speed, the greater the overall energy efficiency and the lower the energy consumed by the vehicle, which thus reduces fuel consumption and pollutant emissions.

\section{Conclusions and Policy Recommendations}

The main objectives of this research were to define the operative features of LMD according to multiple-trip delivery route typology, as well as to measure the energy efficiency and pollutant emissions according to the delivery area, either city center or peri-urban. Thus, this research aims at comparing the environmental performance of different delivery routes, and developing policies tailored to each location.

After carrying out a real data collection campaign, an energy consumption model was calibrated according to the LDV used during the field test. This enabled us to evaluate the vehicle efficiency during deliveries, as well as fuel consumption and pollutant emissions, 
and to identify the most efficient route in terms of environmental performance. The main findings obtained from this research will be discussed in the following.

The environment, in terms of the characteristics of the delivery area, remains a key factor concerning the LMD performance. Indeed, according to the results, LMD operations vary widely depending on whether deliveries are carried out in city center or in the peri-urban delivery area although they may take place within the same metropolitan area.

In the city center, deliveries are denser in terms of number of deliveries per $\mathrm{km}$, characterized by slower operating speeds and performed along similar road section typologies with speed limits lower than $50 \mathrm{~km} / \mathrm{h}$. The overall efficiency fluctuates by around $15 \%$ due to the low operating speed typical for the area. Indeed, along a city center delivery route, there are some micro-areas in which vehicles do not reach operating speeds of 10 $\mathrm{km} / \mathrm{h}$ which makes deliveries less efficient. It was shown that traffic lights, congestion, and pedestrian crossings reduce the average operating speed by up to $57 \%$, which, in turn, reduces the energy efficiency of the vehicle and entails more pollutant emissions. On the other hand, deliveries in the peri-urban area are more disperse, characterized by higher operating speeds and performed along different type of road section typologies: local streets, urban arterials, and motorways. In this area, efficiency fluctuates by around $20 \%$ and reaches $32 \%$ in the optimal case. It results that, in general, the same LDV model performs 33\% better while delivering in the peri-urban area compared to the city center.

According to our results, the overall efficiency is very poor at lower speeds, and consequently the energy efficiency of the vehicle decreases while fuel consumption rises. For the same number of kilometers travelled, the same LDV model consumes more fuel in the city center than in the peri-urban area and thus entails more pollutant emissions. In addition, the results show the high variability of $\mathrm{CO}_{2}$ emissions per $\mathrm{km}$ for lower operating speeds. Considering two different delivery micro-trips carried out by the same LDV and driver, $\mathrm{CO}_{2}$ emissions vary from $35.9 \mathrm{~g} / \mathrm{km}$ to $515.7 \mathrm{~g} / \mathrm{km}$ even if the average speed was around $9 \mathrm{~km} / \mathrm{h}$ for both micro-trips and deliveries were performed in the same delivery area in the city center. In this area, indeed, it is more difficult to maintain a constant speed due to the frequent traffic lights, pedestrian crossings, and intersections which cause interrupted driving. Comparing best performances achieved in both delivery areas, pollutant emissions are significantly lower in the peri-urban case: $15.9 \%$ less $\mathrm{CO}_{2}$ emissions, $16.7 \%$ less $\mathrm{CO}$ emissions, and $18 \%$ less $\mathrm{NO}_{\mathrm{x}}$ emissions.

Within the same delivery area, it is remarkable that there are multiple-trip delivery route typologies that lead to lower pollutant emissions compared to others. In the periurban area, $\mathrm{CO}_{2}$ emissions per $\mathrm{km}$ are $4 \%$ higher along delivery routes that cross residential areas (Route D). This is due to the frequency of pedestrian crossings and intersections which are responsible for frequent accelerations and breaking while delivering. On the other hand, in the city center $\mathrm{CO}_{2}$ emissions are practically the same regardless of the delivery route. Based on the lower operating speeds typical for in city centers and periurban residential area, using medium to large-sized vehicles for delivering there should be avoided. Indeed, this vehicle typology pollutes heavily due to its weight and the frequent start/stops which worsen the environmental impact.

Based on the results, it is clear that due to the lowest efficiency of LDV in the city center and the consequent pollutant emissions, LDV in these areas should be avoided, and deliveries should be performed entirely by no-motorized modes of transport. In peri-urban areas, diesel LDV can be necessary in certain circumstances (i.e., crossing high speed road sections). Yet, this could be complemented with no-motorized transport modes to access residential areas. Indeed, intermodality should be fostered and promoted mainly in periurban areas, e.g., pre-defined fixed routes for a fully loaded LDV which stops at strategic points and transfers the parcels to no-motorized modes of transport, i.e., cargo-bikes, used for deliveries within residential areas.

The optimal solution should be to use LDV only along those routes on which interruptions are minimal, where it is easier to maintain a constant and higher operative speed, and consequently to reduce acceleration and breaking times. Thus, the efficiency of the 
vehicle can be maximized, and fuel consumption kept at a minimum. Since this is almost impossible in the city center, it emerges the urgence to transfer city center deliveries to no-motorized modes.

Based on real data, this research provides an overview for transport planners and policymakers in terms of LMD management, operation, and usage. Moreover, it presents results useful for the optimization of a traditional delivery mode such as LDV. It may help to design emissions reduction strategies for urban freight transport companies to reduce their environmental impact. Further research should expand the study area and include a comparison with electric vehicles which could be made on the basis of a "well-to-wheel" formula. Additionally, future studies can focus on the estimation of LMD cost according to delivery area and multiple-trip delivery route typology.

Author Contributions: A.B.-M.: Literature Review, Data Collection, Data Analysis, Energy Modelling and Calibration, Content planning, Manuscript Writing. A.M.: Research coordinator, Content planning, Manuscript Writing. P.L.-R.: Data Analysis, Energy Modelling and Calibration, Manuscript Writing. D.Á.-M.: Data Analysis, Energy Modelling and Calibration, Manuscript Writing. All authors have read and agreed to the published version of the manuscript.

Funding: This research received no external funding.

Informed Consent Statement: Informed consent was obtained from all subjects involved in the study.

Conflicts of Interest: The authors declare no conflict of interest.

\section{References}

1. EUROSTAT. 2020. Available online: https://ec.europa.eu/eurostat/statistics-explained/pdfscache/1180.pdf (accessed on 10 September 2021).

2. Dingil, A.E.; Schweizer, J.; Rupi, F.; Stasiskiene, Z. Updated models of passenger transport related energy consumption of urban areas. Sustainability 2019, 11, 4060. [CrossRef]

3. European Commission, Directorate General-Mobility and Transport. Transport in the European Union Current Trends and Issues. 2019. Available online: https:/ / ec.europa.eu/transport/sites/default/ files/2019-transport-in-the-eu-current-trends-and-issues. pdf (accessed on 10 September 2021).

4. Marcucci, E.; Le Pira, M.; Gatta, V.; Inturri, G.; Ignaccolo, M.; Pluchino, A. Simulating participatory urban freight transport policy-making: Accounting for heterogeneous stakeholders' preferences and interaction effects. Transp. Res. Part E Logist. Transp. Rev. 2017, 103, 69-86. [CrossRef]

5. Ranieri, L.; Digiesi, S.; Silvestri, B.; Roccotelli, M. A review of last mile logistics innovations in an externalities cost reduction vision. Sustainability 2018, 10, 782. [CrossRef]

6. International Transport Forum. How Urban Delivery Vehicles can Boost Electric Mobility. Available online: https:/ www.itfoecd.org/how-urban-delivery-vehicles-can-boost-electric-mobility (accessed on 28 July 2021).

7. Villa Martinez, R.; Monzon, A. Logística urbana ferroviaria y e-commerce: Análisis de costes externos del modelo M4G (Metro For Goods). In Proceedings of the XIV Congreso De Ingeniería Del Transporte, Burgos, Spain, 6-8 July 2021.

8. Mangiaracina, R.; Perego, A.; Seghezzi, A.; Tumino, A. Innovative solutions to increase last-mile delivery efficiency in B2C e-commerce: A literature review. Int. J. Phys. Distrib. Logist. Manag. 2019, 49, 901-920. [CrossRef]

9. Alliance for Logistics Innovation through Collaboration in Europe-ALICE. A Framework and Process for the Development of a Roadmap towards Zero Emissions Logistics. 2050. Available online: http://www.etp-logistics.eu/wp-content/uploads/2019/1 2/Alice-Zero-Emissions-Logistics-2050-Roadmap-WEB.pdf (accessed on 28 July 2021).

10. Cattaruzza, D.; Absi, N.; Feillet, D.; González-Feliu, J. Vehicle routing problems for city logistics. EURO J. Transp. Logist. 2017, 6, 51-79. [CrossRef]

11. Ragàs Prat, I. Logística urbana. Manual Para Operadores Logísticos y Administraciones Públicas, 1st ed.; Valencia 558-08026; Marge Books: Barcelona, Spain, 2018.

12. Coloma, J.F.; García, M.; Fernández, G.; Monzón, A. Environmental Effects of Eco-Driving on Courier Delivery. Sustainability 2021, 13, 1415. [CrossRef]

13. Monzón, A.; Boggio-Marzet, A. Eco-driving: Eficiencia energética y conducción responsable. Pap. Energ. 2020, 10 , 93-123.

14. Macharis, C.; Melo, S. Introduction-city distribution: Challenges for cities and researchers. In City Distribution and Urban Freight Transport: Multiples Perspectives; Macharis, C., Melo, S., Eds.; Edward Elgar Publishing: Northampton, UK, 2011 ; pp. 1-9.

15. Pronello, C.; Camusso, C.; Rappazzo, V. Last mile freight distribution and transport operators' needs: Which targets and challenges? Transp. Res. Procedia 2017, 25, 888-899. [CrossRef]

16. Faccio, M.; Gamberi, M. New city logistics paradigm: From the "last mile" to the "last 50 miles" sustainable distribution. Sustainability 2015, 7, 14873-14894. [CrossRef] 
17. Marchi, B.; Zanoni, S.; Ferretti, I.; Zavanella, L.E. Stimulating Investments in Energy Efficiency through Supply Chain Integration. Energies 2018, 11, 858. [CrossRef]

18. United Nations, Department of Economic and Social Affairs: World Social Report 2020_-Inequality in a Rapidly Changing World. Available online: https:/ / www.un.org/development/desa/publications/world-social-report-2020.html (accessed on 27 July 2021).

19. CNMC Comisión Nacional de los Mercados y la Competencia. 2020. Available online: http://data.cnmc.es/datagraph (accessed on 28 July 2021).

20. European Union Cordis EU Research Results. The New Synergies of Shopping: E-commerce or 'Bricks and Mortar'? Available online: https:/ / cordis.europa.eu/article/id/429254-the-new-synergies-of-shopping (accessed on 28 July 2021).

21. Zebra. Reinventing the Supply Chain. Available online: https://www.zebra.com/content/dam/zebra_new_ia/en-us/solutionsverticals/vertical-solutions/retail/vision-study / fulfillment-vision-study-report-en-us.pdf (accessed on 10 September 2021).

22. Gevaers, R.; Van de Voorde, E.; Vanelslander, T. Characteristics and typology of last-mile logistics from an innovation perspective in an urban context. In City Distribution and Urban Freight Transport: Multiples Perspectives; Macharis, C., Melo, S., Eds.; Edward Elgar Publishing: Northampton, UK, 2011; pp. 56-71.

23. Freight Leaders Council: La Logistica ai Tempi Dell'e-Commerce. Quaderno 26. 2017. Available online: https://www. freightleaders.org/i-quaderni/ (accessed on 30 July 2021).

24. Aljohani, K.; Thompson, R.G. Impacts of logistics sprawl on the urban environment and logistics: Taxonomy and review of literature. J. Transp. Geogr. 2016, 57, 255-263. [CrossRef]

25. Civitas EU 2020. Smart Choices for Cities. Making Urban Freight Logistics More Sustainable. Available online: https:// civitas. eu/sites/default/files/civ_pol-an5_urban_web.pdf (accessed on 28 July 2021).

26. Savelsbergh, M.; Van Woensel, T. City logistics: Challenges and opportunities. Transp. Sci. 2016, 50, 579-590. [CrossRef]

27. Browne, M.; Allen, J.; Nemoto, T.; Patier, D.; Visser, J. Reducing social and environmental impacts of urban freight transport: A review of some major cities. Procedia-Soc. Behav. Sci. 2012, 39, 19-33. [CrossRef]

28. Navarro, C.; Roca-Riu, M.; Furió, S.; Estrada, M. Designing new models for energy efficiency in urban freight transport for smart cities and its application to the Spanish case. Transp. Res. Procedia 2016, 12, 314-324. [CrossRef]

29. Ermagun, A.; Shamshiripour, A.; Stathopoulos, A. Performance analysis of crowd-shipping in urban and suburban areas. Transportation 2019, 47, 1955-1985. [CrossRef]

30. Wygonik, E.; Goodchild, A.V. Urban form and last-mile goods movement: Factors affecting vehicle miles travelled and emissions. Transp. Res. Part D Transp. Environ. 2018, 61, 217-229. [CrossRef]

31. Mommens, K.; Buldeo Rai, H.; van Lier, T.; Macharis, C. Delivery to homes or collection points? A sustainability analysis for urban, urbanised and rural areas in Belgium. J. Transp. Geogr. 2021, 94, 103095. [CrossRef]

32. Kim, G.; Ong, Y.S.; Heng, C.K.; Tan, P.S.; Zhang, N.A. City vehicle routing problem (city VRP): A review. IEEE Trans. Intell. Transp. Syst. 2015, 16, 1654-1666. [CrossRef]

33. Eglese, R.; Black, D. Optimizing the routing of vehicles. In Green Logitics. Improving the Environmental Sustainability of Logistics; McKinnon, A., Cullinane, S., Browne, M., Whiteing, A., Eds.; Kogan Page: London, UK, 2010; pp. 215-228.

34. Melo, S.; Baptista, P.; Costa, Á. Comparing the use of small sized electric vehicles with diesel vans on city logistics. Procedia-Soc. Behav. Sci. 2014, 111, 1265-1274. [CrossRef]

35. Albergaria de Mello Bandeira, R.; Vasconcelos Goes, G.; Schmitz Gonçalves, D.N.; de Almeida, M.; Machado de Oliveira, C. Electric vehicles in the last mile of urban freight transportation: A sustainability assessment of postal deliveries in Rio de Janeiro-Brazil. Transp. Res. Part D Trans. Environ. 2019, 67, 491-502. [CrossRef]

36. Boggio-Marzet, A.; Monzón, A. Defining Energy (In)Efficiency of Last-Mile Postal Delivery: A Real Case Study in the Madrid Region. In Proceedings of the 10th Young Researchers Seminar, Portorož, Slovenia, 15-17 September 2021.

37. Cuesta, C.; Luque, P.; Mantaras, D.A. State estimation applied to non-explicit multibody models. Nonlinear Dyn. 2016, 86, 1673-1686. [CrossRef]

38. Luque, P.; Mántaras, D.A.; Maradona, A.; Roces, J.; Sánchez, L.; Castejón, L.; Malón, H. Multi-Objective Evolutionary Design of an Electric Vehicle Chassis. Sensors 2020, 20, 3633. [CrossRef]

39. Allonca, D.; Mantaras, D.A.; Luque, P.; Alonso, M. A new methodology to optimize a race car for inertial sports. Proc. Inst. Mech. Eng. Part P J. Sports Eng. Technol. 2019, 233, 312-323. [CrossRef]

40. Jimenez-Palacios, J.L. Understanding and Quantifying Motor Vehicle Emissions with Vehicle Specific Power and TILDAS Remote Sensing. Ph.D. Thesis, Massachusetts Institute of Technology, Cambridge, UK, 1999. Available online: https://dspace.mit.edu/ handle/1721.1/44505 (accessed on 28 July 2021).

41. United States Environmental Protection Agency EPA. Report EPA-420-R-20-019, “Exhaust Emission Rates for Light-Duty on Road Vehicles in MOVES3". 2020. Available online: https:// cfpub.epa.gov/si/si_public_file_download.cfm?p_download_id=54 1810\&Lab=OTAQ (accessed on 28 July 2021).

42. COPERT. The Industry Standard Emissions Calculator. Available online: https://www.emisia.com/utilities/copert/ (accessed on 28 July 2021).

43. European Environment Agency. EMEP/EEA Air Pollutant Emission Inventory Guidebook 2019 Technical Guidance to Prepare National Emission Inventories. EEA Report No 13/2019. Available online: https:/ / www.eea.europa.eu/publications/emep-eeaguidebook-2019 (accessed on 28 July 2021). 
44. EUR-lex Access to European Union Low. Commission Regulation (EU) 2017/1151 of 1 June 2017 Supplementing Regulation (EC) No 715/2007 of the European Parliament and of the Council on Type-Approval of Motor Vehicles with Respect to Emissions from Light Passenger and Commercial Vehicles (Euro 5 and Euro 6) and on Access to Vehicle Repair and Maintenance Information, Amending Directive 2007/46/EC of the European Parliament and of the Council, Commission Regulation (EC) No 692/2008 and Commission Regulation (EU) No 1230/2012 and Repealing Commission Regulation (EC) No 692/2008 (Text with EEA Relevance) Text with EEA Relevance. Available online: http:/ / data.europa.eu/eli/reg/2017/1151/2020-01-25 (accessed on 28 July 2021).

45. Lois, D.; Wang, Y.; Boggio-Marzet, A.; Monzon, A. Multivariate analysis of fuel consumption related to eco-driving: Interaction of driving patterns and external factors. Transp. Res. Part D Transp. Environ. 2019, 72, 232-242. [CrossRef] 